\title{
ASSESSING THE REPEATABILITY OF REFLECTION SEISMIC DATA IN THE PRESENCE OF COMPLEX NEAR-SURFACE CONDITIONS CO2CRC OTWAY PROJECT, VICTORIA, AUSTRALIA
}

\author{
Yousuf Al-Jabri 1*, Milovan Urosevic ${ }^{2}$, Anton Kepic, and Brian Evans ${ }^{4}$ \\ P.D.O., Oman, Curtin University of Technology and CO2CRC, Perth, Australia', \\ Curtin University of Technology and CO2CRC, Perth, Australia ${ }^{234}$ \\ Yousuf.Aljabri@postgrad.curtin.edu.au1,M.Urosevic@curtin.edu.au²,A.Kepic@curtin.edu.au", \\ B.Evans@@urtin.edu.au ${ }^{4}$
}

Key Words: Time-Lapse/near surface conditions

\section{INTRODUCTION}

A depleted Gas Field (Naylor) located in the onshore Otway Basin of Australia (Figure 1) is situated in a tilted fault block structure. After some years of gas production from Naylor-1, the field was abandoned. Subsequently, the field is being used for $\mathrm{CO} 2$ sequestration as a demonstration project, and will be used for monitoring the migration of $\mathrm{CO} 2$ during the injection process into a sandstone reservoir $300 \mathrm{~m}$ down-dip from the monitoring well. Optimum seismic repeatability is critical to the monitoring of the field. In order to assess the relative influences of source types and environmental conditions, a series of repeated 2D seismic test surveys were performed before injection commenced. It was discovered that the absorption of energy in the near surface had much greater effect than anticipated.

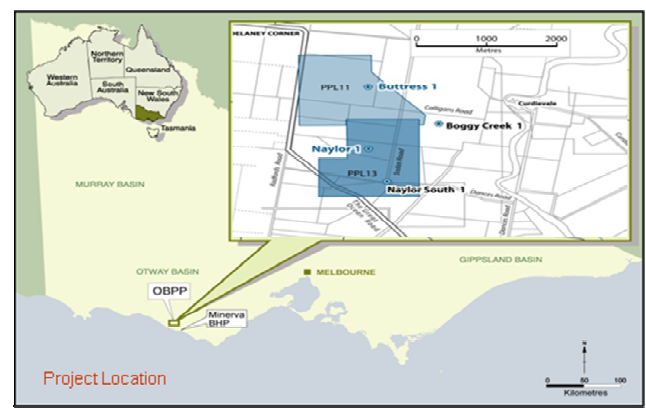

Figure 1: Shows the location of Naylor Field in the south-east of Australia (at Otway Basin).

Seismic modelling experiments were performed to understand the effect of a variable near surface on seismic responses associated with a variety of subsurface conditions. These include the effects of a vertical velocity gradient, vertical density gradient, energy absorption at the near surface, velocity model dependency on 2D seismic data measurements, well logs and field observation. The aim of this work is to better understand the effects of near surface conditions (wet and dry) on seismic imaging, with particular application to the constraints it imposes on the time-lapse 3D seismic response to injected $\mathrm{CO} 2$. A comparison of numerical and field data may allow the changing properties of the reservoir to be better understood in terms of how the rock physics properties respond to surface conditions

\section{MOTIVATION}

Time-lapse or 4D data are increasingly used to study and image the changes in the seismic response induced by the production oil hydrocarbons or the injection of $\mathrm{CO} 2$ into a reservoir. 
Unfortunately, time-lapse seismic changes are also produced by variations in the near-surface conditions, source signature variation, acquisition geometry (positioning and spacing), acquisition equipment, and recording fidelity differences between the surveys, processing methods, and environmental noise. The confidence level during interpreting any seismic changes depends on how good the seismic repeatability is in the area. However, residual differences in the repeated time-lapse data that do not represent changes in the subsurface geology impact the effectiveness of the method. In this paper we show that the changes in near surface ground conditions, specifically saturation of the ground have a very profound effect on seismic repeatability (Figure $2 \&$ Figure 3). A common belief that deployment of the same seismic source and positioning errors are crucial for successful time-lapse seismic should be re-examined in light of our results, which show that these factors are of secondary importance when it comes to land seismic surveys. This may be the case for offshore surveying, but land surveying presents quite different problems- the majority of which can be in the near-surface.

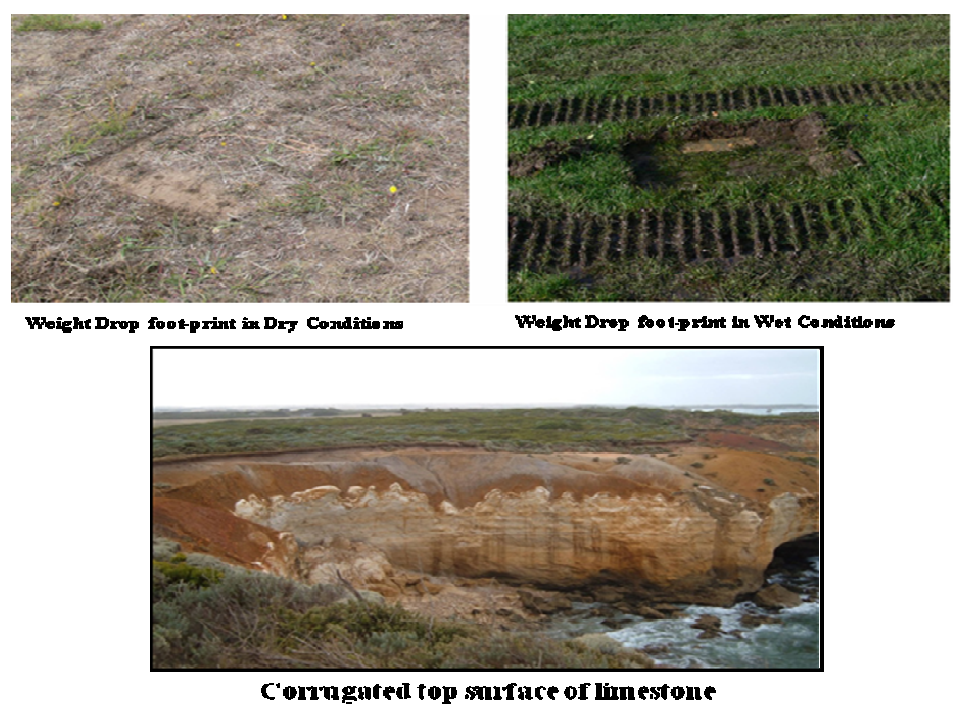

Figure 2: Images of effects of variation of water saturation at the near surface (weight drop impact footprint), and corrugated top surface of limestone in Otway Basin near surface.

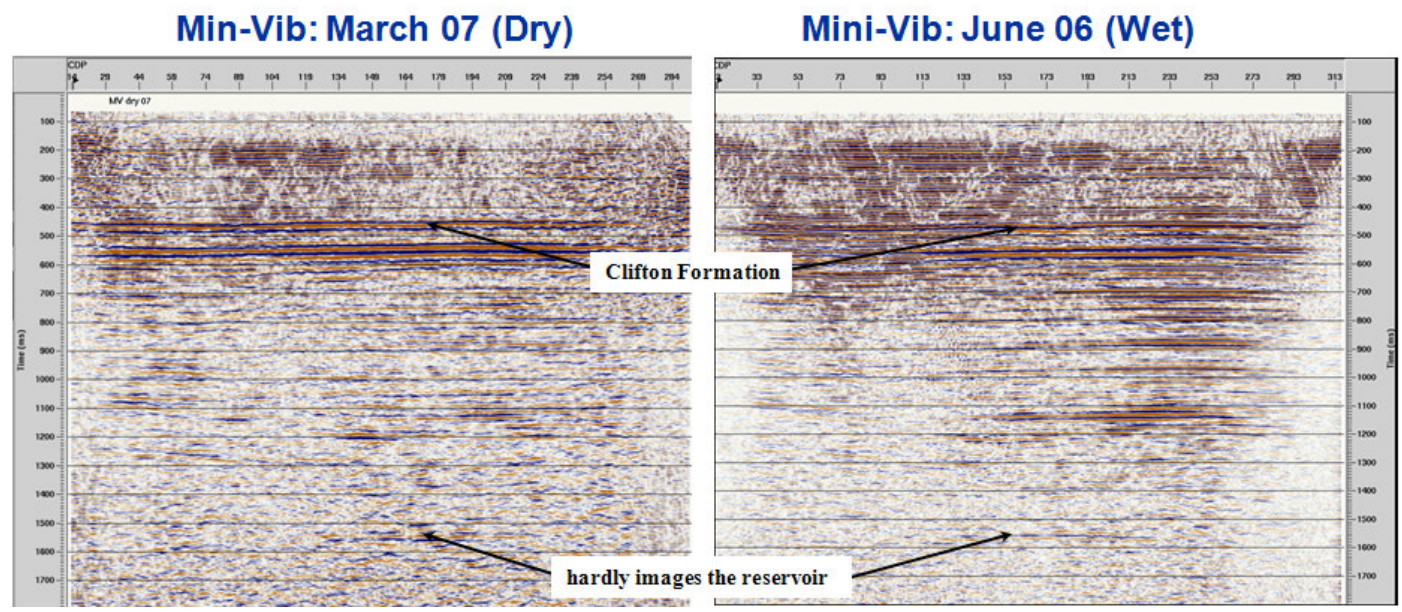


Figure 3: Variation of seismic response for wet and dry conditions of near surface from $2 D$ seismic test lines using the same seismic source and identical acquisition parameters.

\section{METHODOLOGY}

Earth models have been constructed from the well data of CRC-1, 2D seismic test line and field observation. Some geophysicists believe that $90 \%$ of near surface problems come from the portion of soil and clay in the first $6 \mathrm{~m}$ of our model; however, other geophysicists believe that $90 \%$ of near surface problems come from the first top layer of soil of $0.5 \mathrm{~m}$ (pers. Communication). Therefore, we decided to try different models that include and exclude the first top layer of soil to compare change in the seismic response between these different hypotheses (Figures 4 and 5).
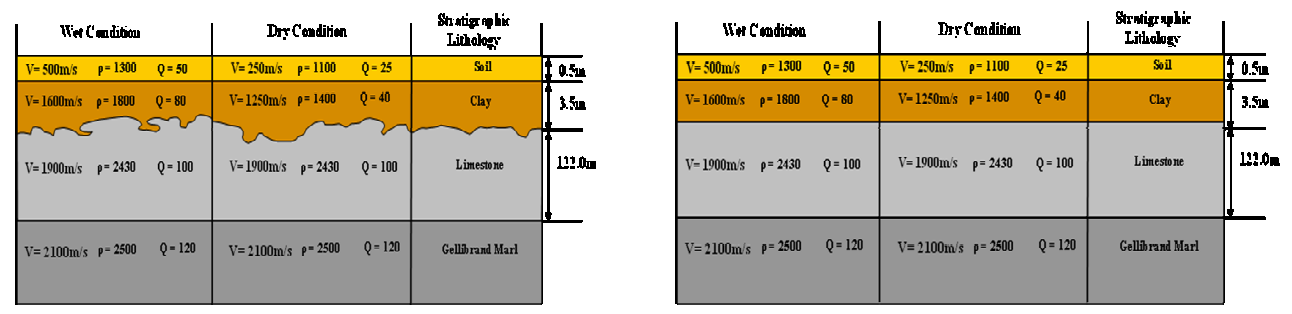

Figure 4: On the left is Model-1, which represents the wet \& dry conditions of near-surface and having a corrugated top surface of the limestone that includes a top soil layer, and the right hand side model (Model2) represents the wet \& dry conditions of near-surface, but has a flat top surface of the limestone and includes a top soil layer

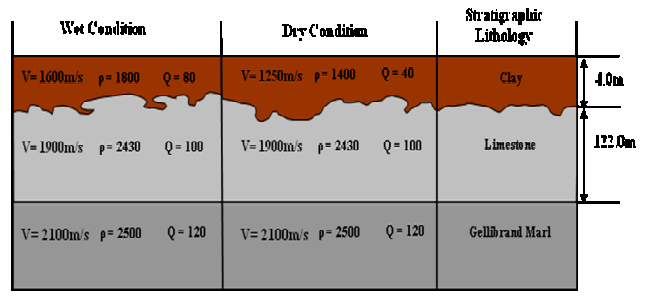

Figure 5: Model-3 represents the wet \& dry conditions of near-surface with a corrugated top surface of the limestone, but excludes a top soil layer

\section{RESULTS}

The seismic repeatability is measured at the Gellibrand Marl formation which is at $122 \mathrm{~m}$ depth from the surface using the following equation:

$$
N M R S=\frac{200 R M S\left(a_{t}-b_{t}\right)}{R M S\left(a_{t}\right)+R M S\left(b_{t}\right)}
$$

The non-repeatability of seismic amplitudes in two traces, $a_{t}$ and $b_{t}$, can be measured by normalized root-mean-square difference (NRMS), defined in time gate $t$ by the rms of the 
difference between $a_{t}$ and $b_{t}$ normalized by the mean rms of the two traces and expressed as a percentage.
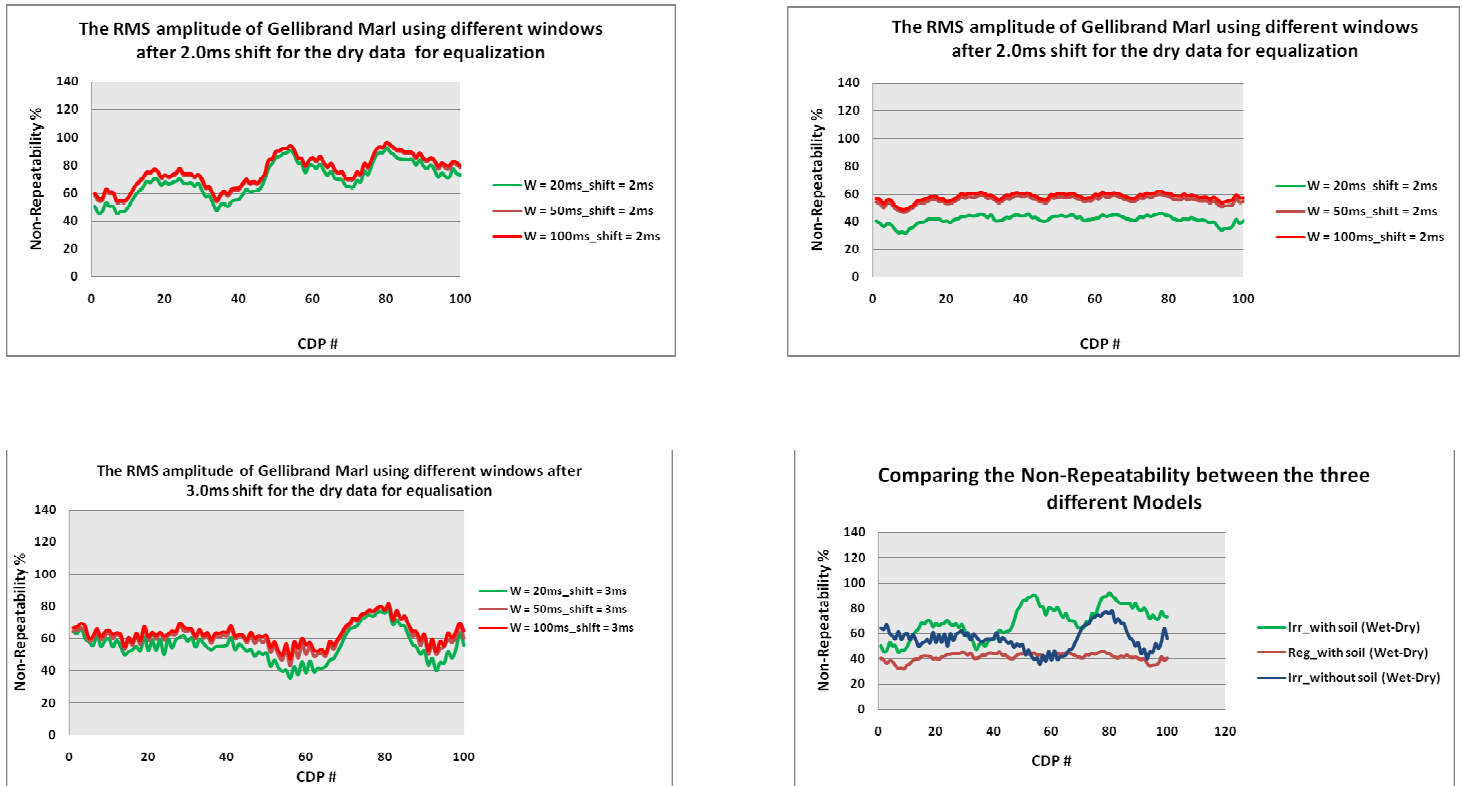

Figure 5: The top lift hand side graph shows the non-repeatability between wet \& dry condition of model-1 which measured at different window (20ms, 50ms, 100ms) around Gellibrand Marl horizon. The top right hand side graph shows the non-repeatability between wet \& dry condition of model-2 which was measured at different windows (20ms, 50ms, 100ms) around Gellibrand Marl horizon. The bottom lift hand side graph shows the non-repeatability between wet \& dry condition of model-3 which was measured at different windows (20ms, 50ms, 100ms) around Gellibrand Marl horizon. The bottom right hand side graph shows the comparison of non-repeatability between wet \& dry condition of all three models which was measured at a window of 20ms around Gellibrand Marl horizon.

\section{CONCLUSIONS}

Seismic amplitude is more sensitive than seismic velocity to wet and dry conditions as $4 \mathrm{D}$ seismic simulation predicts only 2-3\% change in the velocity (Ruiping Li et al, 2006)

$>$ Change in water table can influence the seismic response.

$>$ Acquisition operation should be done at times of the same condition of the near surface for the 4D seismic.

$>$ We believe that both top soil and underground water level, with respect to the limestone top surface will determine the level of seismic repeatability.

$>$ Vital to acquire repeat 3D surveys under similar ground conditions (also applies to VSP)

$>$ Future experiments need to analyse the effect of water saturation in the near surface.

\section{ACKNOWLEDGMENT}

Yousuf Al-Jabri would like to thank the Cooperative Research Centre for Greenhouse Gas Technologies (CO2CRC), for providing me the full access to Otway Basin Pilot Project (OBPP) 
data base. My acknowledgement also goes to Petroleum Development Oman (PDO) for awarding me a PhD scholarship. I would like to acknowledge Tesseral Technologies Inc. for the 2D Tesseral modeling software.

\section{REFERENCES}

Al-Jabri Y., Urosevic M., and Kepic A., 2008, The effects of the near-surface weathered zone on the $\mathrm{CO}_{2}$ time-lapse monitoring program at Naylor-1, CO2CRC Otway Project, Victoria, Australia; CO2CRC Symposium 2008, Queenstown, New Zealand, 1 - 5 December 2008 (accepted).

Al-Jabri Y. and Urosevic M., 2008, The applicability of vibroseis sources for the land seismic time-lapse surveys; CO2 sequestration field, CO2CRC Otway Project, Victoria, Australia; Vibroseis Workshop 2008 Prague, Czech Republic, 13 - 15 October 2008 (accepted).

Al-Jabri Y., Urosevic M., and Kepic A., 2008, The effect of corrugated Lime-stone and the changing of the near surface conditions on $\mathrm{CO}_{2}$ monitoring program at Naylor-1, CO2CRC Otway Project, Victoria, Australia; First EAGE $\mathrm{CO}_{2}$ Geological Storage Workshop - Budapest, Hungary, 29 \& 30 September 2008.

Al-Jabri Y., Urosevic M., Evans B. and Sherlock D., 2008, Understanding seismic repeatability in the presence of irregular near surface conditions (karst), CO2CRC Otway Project, Victoria, Australia; SEG \& EAGE Summer Research Workshop 2008 - Vancouver, Canada, 7-12 September 2008.

Baker Gregory S., 1999. Processing Near-Surface Seismic-Reflection Data: A Primer. SEG Course Notes Series9. Tulsa: Department of geology. State University of New York at Buffalo, Society of Exploration Geophysicists.

Calvert, R., 2005, Insights and methods for 4D reservoir monitoring and characterization: Society of Exploration Geophysicists. CGG, 2000, Final Report: Seismic Data Processing OCV00 Curdie Vale 3D; period: May September for Santos, Ltd.

Ruiping Li, Milovan Urosevic1, and Kevin Dodds; 2006. Prediction of 4D seismic responses for The Otway Basin CO2 sequestration site. Cooperative Research Centre for Greenhouse Gas Technologies. Department of Exploration Geophysics, Curtin University of Technology, CSIRO Petroleum, AustraliaSherlock D., Urosevic M., Kepic A., and Dodds K., 2007; Time-lapse seismic monitoring of Otway Project; planning and acquisition repeatability testing, CO2CRC Symposium 2007, Perth, Australia.

Urosevic, M., Sherlock D., Kepic, A., Nakanishi S. and Tcherkashnev S., K., Time lapse VSP program for Otway basin CO2 sequestration pilot project”, 70th EAGE Conference \& Exhibition — Rome, Italy, 9 - 12 June 2008.

Urosevic, M., Sherlock D., Kepic, A., and Dodds, K., "Land seismic acquisition repeatability for timelapse monitoring of CO2 sequestration" 19th International Conference of Australian Society of Exploration Geophysics, Perth, WA (2007b). 